tackled, to widen the acceptance and use of promising techniques and to fill gaps so far as possible. By the end of this preparatory period it should be possible to gather sufficient ship-time and funds together to make a combined assault on one of the least-known and most promising areas. The Indian Ocean was thought to fill this requirement. Its submarine topography and water circulation are not very well known ; the complete reversal of wind in two halves of the year affords a unique opportunity for studying how quickly the currents and water layers respond to wind changes, and there is much biological and geological work to be done.

Such a programme cannot be carried out without enthusiastic support of existing national and international organizations, and fairly immediate practical aims must be urged as well as long-term need for better understanding of the oceans. One growing need is for a better appreciation of the effect of using the oceans as a receptacle for the waste products of industry. Even now we need to know what effects the water circulation and the migrations of marine animals are likely to have on the transport of radioactive material deposited in the ocean. We no longer look on the oceans as infinite and readily available sources of food, but we are more and more conscious that better understanding of their physies and biology will be a great help to the successful use of their tapped and untapped resources. The study of elimate and weather has also advanced to the stage where it begins to need more understanding of the circulation of heat in the oceans and their interchanges with the atmosphere.

The idea of making a start in the Indian Ocean is likely to receive the approval of most international authorities interested in the oceans. Unesco will have opportunities to arrange the training of scientists from countries around the Indian Ocean, and to make the possibilities known to more countries. The Food and Agriculture Organization is very interested in the striking fluctuations in the fisheries in the northern part of the Ocean, and their effect on the local populations. The scientific unions will recognize the value of now and widespread measurements to basic as well as to the regional problems.

The idea will not go unchallenged. There are not many oceanographers, and they are not likely to welcome new obligations. It was not easy for oceanography to take part in the International Geophysical Year. The scheme that is gradually being formulated is, however, a reasonable plan, with plenty of encouragement for individual effort and inter-laboratory collaboration, as well as measures for promoting co-operation on a larger scale than can be achieved without special organization. The plan is also arranged to take full advantage of the knowledge and experience of existing organizations such as the scientific unions, which are mainly concerned with basic studies of particular aspects of the subject, and the regional associations such as the International Council for the Exploration of the Sea, the Pacific Science Council, and others, which grow in importance but are primarily concerned with regional problems. One of the fears most expressed is that there is too much overlapping between all the new and old interests, and too many conferences. As the subject grows we must work for some unification, but it is only fair to admit that there has been so far no forum in which specialists in all aspects of the subject meet together, and we already see growing enthusiasm and sharing of responsibilities.

G. E. R. Deacon

\section{THE TECHNICAL ASSISTANCE BOARD REPORT FOR 1956}

$T$ HE annual report of the Technical Assistance Board for 1956* to the Economic and Social Council of the United Nations records that a higher initial earmarking of funds for the participating organizations and the secretariat-up to 97.3 per cent of the approved programme, compared with only 56 and 71 per cent, respectively, in 1954 and 1955 - with consequent smoother implementation of the programme, was possible ; also that 93 per cent of the programme was delivered to the centres requesting assistance during the year. Of the $25 \cdot 3$ million dollars expended on field operations during 1956, 18 per cent was for the 2,128 fellowships, including study grants awarded, for which 88 countries served as hosts ; 13 per cent on equipment and supplies for training and demonstration; and the remaining 69 per cent to finance the 2,346 experts supplied. These experts were drawn from sixty-seven nationalities, and despite difficulties in recruitment in certain specialized fields, this total is 238 higher than in 1955; the professional standard was maintained at a high average level, although there are indications that the Expanded Programme does not offer conditions of service adequate to attract men and women of the quality desired in the absence of idealistic motives.

Technical assistance was provided in fifty-six sovereign States and in forty-seven dependent territories; but soundly based requests for technical assistance greatly exceed in volume the possibilities of meeting them, and the report suggests that even if increased resources become available it may be wise to concentrate on the neediest countries and territories. Some adjustments in the geographical distribution have already been made : in 1954, VietNam, Cambodia, Laos, Sudan, Tunisia, Morocco and Ghana received technical assistance under the Expanded Programme amounting to 240,000 dollars ; in 1956 they received 780,000 dollars, and for 1957 it will be about 1.5 million dollars. In many of the less-developed countries, requests for assistance place increasing emphasis on the development of adminis. trative and technical services. The ability of a country to develop its resources and to take full advantage of technical assistance depends largely on the stage of development of its government and administration, and increasing attention is likely to be given to this aspect as the resources of the programme expand.

The Technical Assistance Board is examining the high proportion of continuing projects-915 out of the 1,334 projects in operation in 1956 were started in 1955 or earlier-with reference to the possibility that the programme as a whole is becoming rigid. The continuing programmes accounted for 85 per cent of the expenditure on the field-programme, but this was largely due to the overlapping of programme years, although there are a few genuine long-term projects. Nevertheless, the chapter on evaluation of the programmes introduced this year is intended to be a regular feature of future annual reports, and it is hoped that governments will co-operate in pro-

* Annual Report of the Technical Assistance Board for 1956. Pp. 244. (New York: United Nations, 1957.) 
viding the material on which an effective annual review can be based. The number of pledged contributions again increased : for 1956, seventy-seven countries pledged 28.8 million dollars, and for 1957 some eighty countries have already promised about 30.8 million dollars. Nevertheless, as already noted, the financial resources fall far short of what is required to meet the demand, and financial uncertainty still hampers orderly planning. It would be difficult to over-estimate the gain for the Expanded Programme if the Board and Participating Organizations could reasonably count on the expansion of its resources over the next five years to the 50 million dollars a year envisaged.

In evaluating the programme, the report this year emphasizes the increasing effectiveness of co-ordination between the Expanded Programme and other multilateral and bilateral programmes in the assisted countries, and the recipient countries were also agreed as to the value of the contribution made to their national development, and that had more funds been available the three types of assistance-experts, fellowships and equipment-could have been com. bined more effectively to produce a better balanced economy. With few exceptions, the international experts proved not only technically competent but able also to acclimatize themselves quickly and to collaborate effectively. Of the 530 fellowship holders in some eighteen countries, all but 6 per cent now occupy positions where their training can be put to effective use; and although many had fairly recently returned, 45 per cent were already occupying positions of greater responsibility. The Board was also satisfied that all the equipment and supplies provided under the Expanded Programme were effectively utilized.

Almost a third of the report, apart from the appendixes, is occupied by accounts of some projects in operation in 1956. Many of these are of real interest to the scientist and technologist, but only a few can be selected to illustrate what is being done. In view of the direct relation between the development of potato blight and the meteorological environment of the growing crops, the Government of Chile requested help from the World Meteorological Organization to apply meteorological science to the control of potato blight in particular and to other problems of agriculture, and an expert from the Meteorological Service of Ireland was assigned to advise the Chilean Government. While the main purpose of the Chilean authorities was to lay the foundations for an advisory service on the application of fungicides, it also sought answers to other questions on the relation between blight and weather conditions and the areas suitable for testing or growing seed potatoes. Partial answers were provided to these questions which can be amplified and confirmed when more complete data on weather and the incidence of disease are available, criteria used in Ireland for detecting and forecasting blight weather proving equally applicable in Chile, and the Chilean authorities are setting up a network of agro-meteorological stations at their agricultural experimental farms.

At the request of the East Africa High Commission a mission of two meteorological experts was appointed to investigate the meteorological factors in the control of the desert locust and advise on the application of meteorological science to that end. Excellent progress is being made in a detailed and critical synoptic analysis of locust events in co-operation with all the meteorological services concerned, as well as in collaboration with the Anti-Locust Research Centre in London. A Unesco mission on arid-zone research at Recife in Brazil has led to many other requests for such assistance, including a geological and hydrogeological study for dam on the River Paraguay and the creation of a diploma in hydrogeological studies at the Engineering School at Recife. The establishment of a forest research laboratory for the Philippines, assistance in vocational and technical education in Turkey which led to the production of a five-year-plan for the vocational and technical education of men and boys, assistance given to Indian industry in the improvement of efficiency and productivity, the development of civil aviation services in Indonesia, technical as well as legal assistance to civil aviation in Salvador, the eradication of malaria in Mexico and tuberculosis surveys in Africa are other projects briefly described in the report which can only be mentioned.

\section{THE NUFFIELD FOUNDATION REPORT FOR 1956-57}

$T$

$\mathrm{HE}$ wide range of the projects which the Nuffield Foundation supports is once again illustrated by the twelfth report of the Foundation, which covers the year ended March 31, 1957. The introduction to the report reiterates that the Foundation's aim is to assist promising work which for some reason is not attracting support from elsewhere and, after enumerating various purposes which the policy of the Foundation does not allow it to assist, points out that the Foundation subscribes to the view that the pursuit of new knowledge is as much the duty of a university as is the dissemination of existing knowledge. Accordingly, the Foundation does not feel called to assist the everyday investigational work of a university department.

Of the grants for science in the United Kingdom, those for biological research, which totalled $£ 54,545$, included two further grants of $£ 725$ and $£ 2,500$ to Dr. Dorothy Crowfoot Hodgkin's unit in the Laboratory of Chemical Crystallography, Oxford, for work on X-ray analysis of large molecules ; $£ 5,000$ in support of work in the Department of Zoology, Liverpool, on the initial causes of mucosal damage in patients with peptic ulcer and on the evolution of mimicry in polymorphic butterflies with a view of showing how much the effect of major genes can be modified as a result of the evolution of a new gene-complex by natural selection; a further grant of $£ 14,000$ over five years in support of the two units in the Department of Zoology and Comparative Anatomy, Oxford, working on evolution in wild populations, industrial melanism, analysis of the causation of behaviour (with emphasis on sensory perception prior to learning and on motivation), the survival value of various anti-predator devices and adaptive radiation in evolution ; $£ 7,400$ over three years in support of Prof. H. E. Street's work at the University College of Swansea on the nutrition and metabolism of excised root cultures; and $£ 2,000$ over three years to the University of Durham for work on the hatching mechanism of the potato-root eelworm. The grant towards the work on non-specific immunity at the Lister Institute of Preventive Medicine has been renewed for a further five years at the rate of $£ 3,000$ a year. Other grants for scientific research 